\title{
Regulatory Aspects of the Human Factors Engineering Process in Control Room Modernization
}

Jacques Hugo, Jeffrey Joe

June 2017

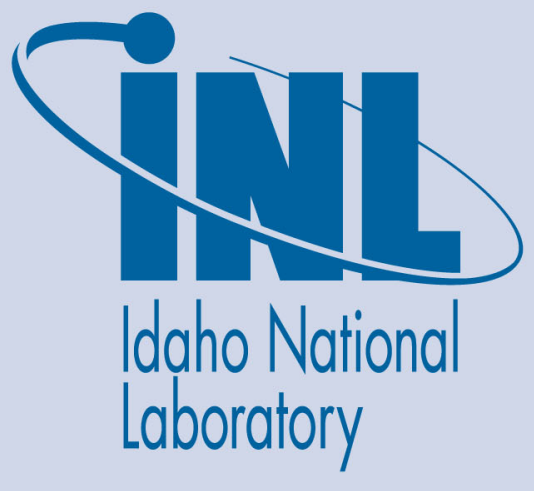

The INL is a U.S. Department of Energy National Laboratory operated by Battelle Energy Alliance 


\title{
Regulatory Aspects of the Human Factors Engineering Process in Control Room Modernization
}

\author{
Jacques Hugo, Jeffrey Joe
}

June 2017

Idaho National Laboratory Idaho Falls, Idaho 83415

http://www.inl.gov

Prepared for the

U.S. Department of Energy

Under DOE Idaho Operations Office

Contract DE-AC07-05ID14517 
INL/EXT-17-42190

\title{
Human Factors Engineering Aspects of Modifications in Control Room Modernization
}

\author{
Jacques Hugo \\ Gordon Clefton \\ Jeffrey Joe
}

June 2017

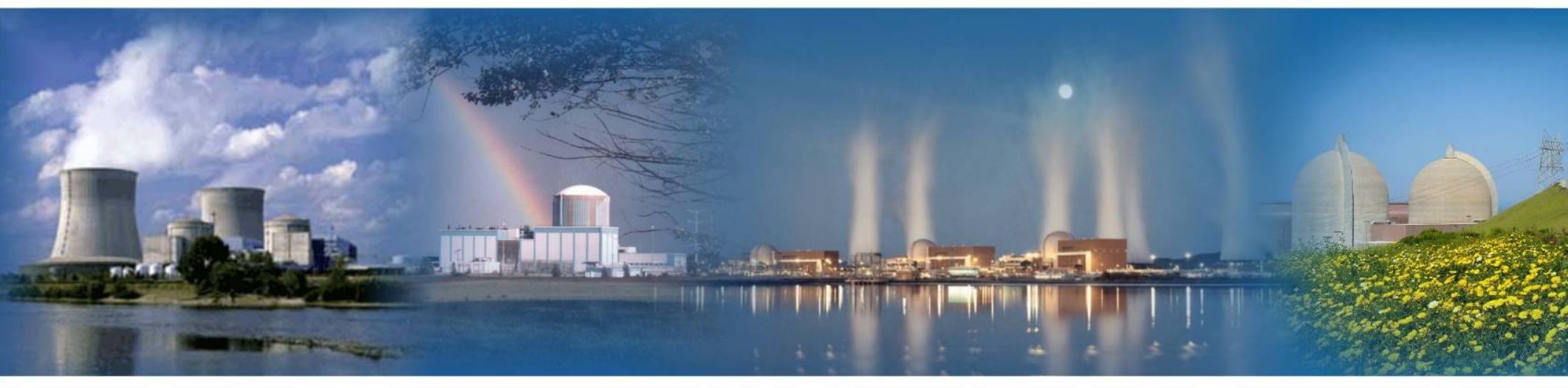

The INL is a U.S. Department of Energy National Laboratory operated by Battelle Energy Alliance 
THIS PAGE INTENTIONALLY BLANK 


\section{DISCLAIMER}

This information was prepared as an account of work sponsored by an agency of the U.S. Government. Neither the U.S. Government nor any agency thereof, nor any of their employees, makes any warranty, expressed or implied, or assumes any legal liability or responsibility for the accuracy, completeness, or usefulness, of any information, apparatus, product, or process disclosed, or represents that its use would not infringe privately owned rights. References herein to any specific commercial product, process, or service by trade name, trade mark, manufacturer, or otherwise, does not necessarily constitute or imply its endorsement, recommendation, or favoring by the U.S. Government or any agency thereof. The views and opinions of authors expressed herein do not necessarily state or reflect those of the U.S. Government or any agency thereof. 
THIS PAGE INTENTIONALLY BLANK 
INL/EXT-17-42190

Revision 0

\title{
Human Factors Engineering Aspects of Modifications in Control Room Modernization
}

\author{
Jacques Hugo \\ Gordon Clefton \\ Jeffrey Joe
}

June 2017

\section{Idaho National Laboratory Idaho Falls, Idaho 83415}

Prepared for the

U.S. Department of Energy

Office of Nuclear Energy

Under DOE Idaho Operations Office

Contract DE-AC07-05ID14517 
THIS PAGE INTENTIONALLY BLANK 


\section{ABSTRACT}

This report addresses control room modernization projects in the U.S. nuclear industry and the need for guidance on the integration of human factors considerations into the digital upgrade modification processes. The report pays specific attention to the integration of principles described in NUREG-0711 (Human Factors Engineering Program Review Model) and how supplementary guidance can help to raise general awareness in the industry regarding the complexities of control room modernization projects created by many interdependent regulations, standards and guidelines. The report also describes how human factors engineering principles and methods provided by various resources and international standards can help in navigating through the processes of digital upgrade modifications. In particular, the integration of human factors engineering guidance into digital upgrade modifications can help reduce uncertainty and risk related to technical bases for digital upgrades that will avoid the introduction of new failure modes. 
THIS PAGE INTENTIONALLY BLANK 


\section{CONTENTS}

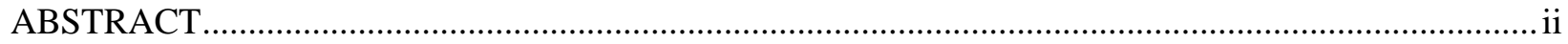

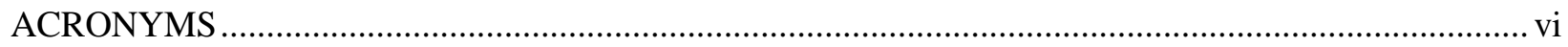

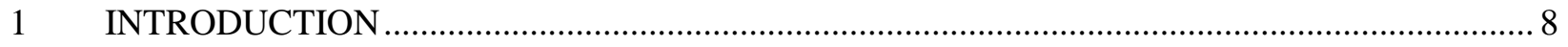

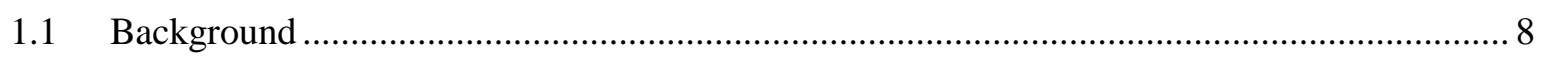

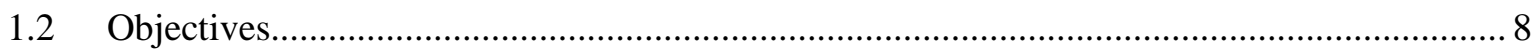

1.3 Types of Nuclear Power Plant Modifications ................................................................. 9

1.3.1 Domestic Nuclear Power Plant Modifications ......................................................... 9

1.3.2 International Nuclear Power Plant Modifications ..................................................... 10

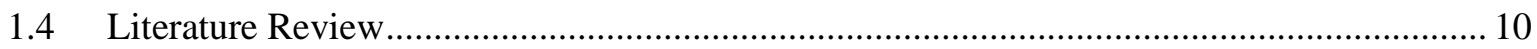

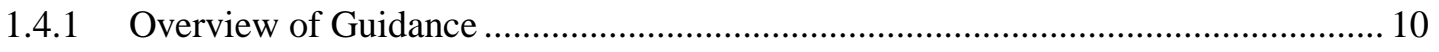

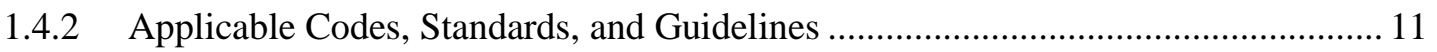

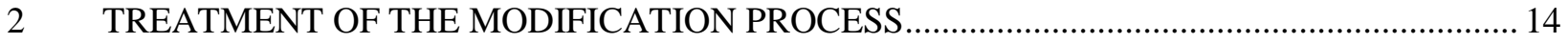

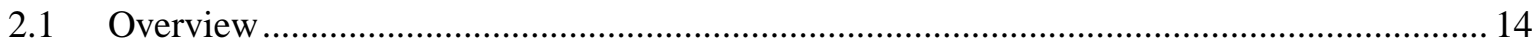

2.2 The plant's design and licensing bases .............................................................................. 14

2.2.1 Determining the applicability with 10 CFR 50.59 ................................................... 15

2.2.2 Guidelines for Response to the 10 CFR 50.59 Screening Criteria............................. 18

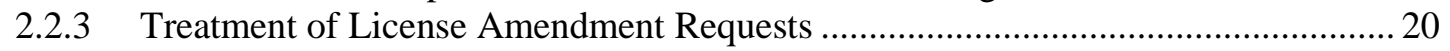

2.3 General Licensing Considerations for Modifications ...................................................... 21

2.4 Management of the HFE Aspects of Modifications.......................................................... 21

2.4.1 Human Factors Engineering inputs to 10 CFR 50.59 ........................................... 21

2.4.2 Applying Human Factors Impact Screening Criteria ................................................. 25

2.4.3 Example: Treatment of the 10 CFR 50.59 evaluation.............................................. 25

2.5 The Human Factors Engineering Program Plan........................................................... 27

2.5.1 Development of an HFE Graded Approach ................................................................. 32

2.5.2 Identification of the Required Level of HFE Activities.............................................. 33

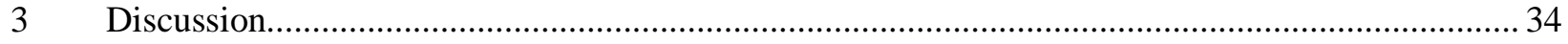

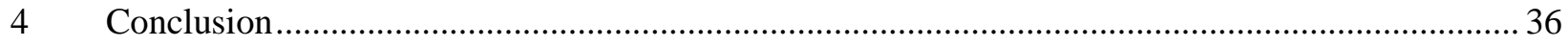

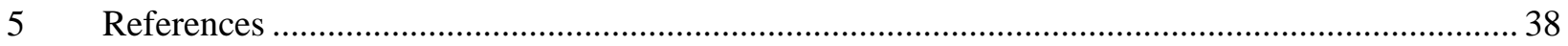

\section{FIGURES}

Figure 1: 10 CFR 50.59 Process (Adapted from NEI 96-07) ................................................................... 16

Figure 2: Human Factors Aspects of the 50.59 Evaluation Process ........................................................... 23

Figure 3: HFE Elements described in NUREG-0711, Rev 3 ............................................................... 29

Figure 4: Human Factors Engineering Process (NUREG-0711) .......................................................... 31 


\section{TABLES}

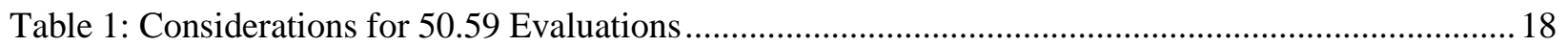




\section{ACRONYMS}

CFR

DCS

DOE

DRPI

EPRI

HFE

FMEA

FSAR

HAZOP

HRA

HSI

HSSL

HFEPP

IAEA

IEEE

I\&C

II\&C

INL

LAR

LWRS

MCR

NEI

NPP

NRC

NRR

NUREG

OER

PRA

PWR

R\&D

RPI

RSR

SAR
Code of Federal Regulations

Distributed Control System

Department of Energy

Digital Rod Position Indicator

Electric Power Research Institute

Human Factors Engineering

Failure Modes and Effects Analysis

Final Safety Analysis Report

Hazard and Operability (study)

Human Reliability Analysis

Human-System Interface

Human System Simulation Laboratory

Human Factors Engineering Program Plan

International Atomic Energy Agency

Institute of Electrical and Electronics Engineers

Instrumentation and Control

Instrumentation, Information, and Control

Idaho National Laboratory

License Amendment Request

Light Water Reactor Sustainability (program)

Main Control Room

Nuclear Energy Institute

Nuclear Power Plant

Nuclear Regulatory Commission

Nuclear Reactor Regulation

Nuclear Regulation

Operating Experience Review

Probabilistic Risk Assessment

Pressurized Water Reactor

Research and Development

Rod Position Indicator

Results Summary Report

Safety Analysis Report 
SRP

SSC

TCS

U.S.

UFSAR

V\&V

VDU
Standard Review Plan

Structures, Systems, and Components

Turbine Control System

United States

Updated Final Safety Analysis Report

Verification and Validation

Visual Display Unit 


\section{HUMAN FACTORS ENGINEERING ASPECTS OF MODIFICATIONS IN CONTROL ROOM MODERNIZATION}

\section{INTRODUCTION}

\subsection{Background}

The United States (U.S.) Department of Energy’s (DOE) Light Water Reactor Sustainability (LWRS) program has the overall objective to sustain the operation of existing commercial nuclear power plants (NPPs). To accomplish this objective, the Advanced Instrumentation, Information, and Control (II\&C) Systems Technologies pathway conducts research and development to address aging and reliability concerns with the legacy instrumentation and control (I\&C) and related information systems of the U.S. operating LWR fleet. The major goals for this effort are to ensure that legacy analog II\&C systems are not life-limiting issues for the LWR fleet, and also to implement digital II\&C technology in a manner that enables broad innovation and business improvement in NPPs.

To continue meeting safety and reliability requirements while controlling operating costs, operators of nuclear power plants must be able to replace and upgrade equipment in a cost-effective manner. Upgrades to plant equipment and especially I\&C systems typically involve either replacement of analog devices with more modern digital technology, or updating existing digital equipment. However, the use of digital technology is raising new design, implementation, and integration issues. For example, existing guidance on digital upgrade modifications present a number of human factors challenges that are difficult to interpret to ensure regulatory compliance. These challenges are primarily related to difficulties that licensees face in the analyses required to accurately respond to some of the questions in 10 Code of Federal Regulation (CFR) 50.59 [1] evaluations. As a result, nuclear plant operators need up-to-date guidance to provide all stakeholders a common framework and understanding of how to apply the 10 CFR 50.59 process to activities involving digital modifications.

Substantial guidance on the human factors engineering (HFE) aspects of digital upgrades has already been developed to support licensees embarking on control room modernization. For example, Electric Power Research Institute (EPRI) reports 1010042 [9] and 3002004310 [8] offer current technical guidance. Since control room modernization projects are still relatively uncommon in the U.S. nuclear industry, the necessary knowledge and experience required to manage all the complexities of such projects, especially the regulatory aspects, are lacking. In addition, much of the available guidance itself is complex and has not been used in digital upgrade modifications yet.

The lack of focused guidance has prompted a fresh work effort in the LWRS program to develop practical, simplified guidance for the integration of human factors aspects of control room modernization. This work forms part of the research and development (R\&D) under the II\&C pathway of the LWRS program. This includes R\&D to address HFE aspects of the processes that utilities incorporate when they embark on control room modification projects.

\subsection{Objectives}

The main objective of this report is to provide supplementary guidance on the integration of human factors considerations into the processes used for digital upgrades in nuclear power plant control rooms. 
Secondary objectives are to:

- Raise general awareness in the industry regarding the complexities of control room modernization projects created by many interdependent regulations, standards, and guidelines.

- Discuss the application of HFE principles and methods provided by resources such as the EPRI human factors guide and international standards like Institute of Electrical and Electronics Engineers (IEEE) 1023 [6] in navigating through the processes of digital upgrades.

- Discuss the integration of HFE guidance into digital upgrade modifications to help reduce uncertainty and risk related to technical bases for digital upgrades that will avoid the introduction of new failure modes. This would apply specifically to reducing uncertainty that human-system interface (HSI) changes could lead to potential adverse effects.

- Provide an overview of the status and progress of research aimed at developing HFE guidance for control room modernization, including the results achieved and lessons learned from the application of current regulation and guidelines on digital upgrade modifications. This will focus in particular on such documents as Nuclear Energy Institute (NEI) 01-01 [3], NEI 96-07 Appendix D [4], NEI 16-16 [14], NUREG-0711 [10], EPRI 3002004310, and related documents.

\subsection{Types of Nuclear Power Plant Modifications}

\subsubsection{Domestic Nuclear Power Plant Modifications}

Under the U.S. Nuclear Regulatory Commission (NRC), nuclear plants make modifications to safety related equipment using a License Amendment Request (LAR) process and their non-safety related equipment using their on-site engineering processes. The decision on which path to follow is based on the process described in 10 CFR 50.59 which includes a screening section and an evaluation section. 10 CFR 50.59 establishes the conditions under which licensees may make changes to a plant, its License, or conduct tests/experiments without prior NRC approval and without submitting a license amendment request.

LAR modifications follow NEI 01-01 and NRC Interim Staff Guidance DI\&C-ISG-06 [16]. The treatment of LARs for control room modernization are discussed further in Section 2.2 below.

To proceed with a modification outside the LAR process, a design must successfully answer all the questions of the 10 CFR 50.59 process and sufficient document the answers so that any NRC review of the documentation will support the decision. 10 CFR 50.59 provides a threshold for regulatory review of the proposed changes but not final deteminination of safety.

The principles for managing modifications are the same for all categories, but in each step of the modification process the path of the modifications determines the depth and breadth of the safety review and the regulatory control applied. These principles are described extensively in the following documents:

- 10 CFR 50.59: Changes, Tests and Experiments [1]

- $\quad$ NRC Inspection Manual [2]

- $\quad$ NEI 01-01: Guideline on Licensing Digital Upgrades (to be superseded by NEI 96-07, Appendix D: Supplemental Guidance for Application of 10 CFR 50.59 to Digital Modifications)

- $\quad$ NEI 96-07: Guidelines for 10 CFR 50.59 Evaluations, and

- EPRI 3002004310: Human Factors Guidance for Control Room and Digital Human-System Interface Design and Modification: Guidelines for Planning, Specification, Design, Licensing, Implementation, Training, Operation, and Maintenance for Operating Plants and New Builds. 
Additional guidance documents are discussed in Section 1.3.2 and the treatment of the human factors aspects of the modification process is discussed in Section 2.

\subsubsection{International Nuclear Power Plant Modifications}

The International Atomic Energy Agency (IAEA) defines modifications relating to plant configuration as any permanent or temporary alterations to structures, systems and components, process software, operational limits and conditions, or operating procedures. This includes any replacement or refurbishment of existing structures, systems and components. This does not include the replacement of a component by an equivalent component in recognized maintenance activities (what is often called "likefor-like replacements”), for example, an analog device replaced by a digital equivalent.

The three categories of modifications, as described in IAEA NS-G-23 [5], can be summarized as follows:

Category 1: Modifications in this category may have a significant effect on the radiological risk or may involve an alteration of the principles and conclusions of the plant's licensing and design bases. Such modifications may involve changes in the set of design basis accidents, or they may alter the technical solutions adopted for meeting the safety goals or lead to changes in the operating rules. Modifications in Category 1 necessitate thorough analysis and may also necessitate prior regulatory approval, a License Amendment, or a new license.

Category 2: Modifications in this category include changes in safety-related items or systems and in operational approaches and/or procedures, and usually necessitate an update of the Safety Analysis Report (SAR) or other licensing documents. Such modifications have a minor influence on safety and no significant alteration to the plant's licensing and design bases. Typically no changes the licensing documents are required. In the design phase for Category 2 modifications, it should be determined whether there are negative side effects, such as degradation of safety features or an expectation of causing significant radiation exposure in making the modification. The operating organization is required to contact the regulatory body, in accordance with established procedures.

Category 3: This category covers minor modifications that can be characterized as follows:

- The modification has no consequences for safety;

- The items to be modified are classified as items not important to safety and are not mentioned in the licensing documents; and

- The modification, even if designed or implemented incorrectly, could not lead to a significant increase in risk.

Note that the U.S. NRC does not adhere to this categorization scheme defined by the IAEA for NPP modifications. It is nevertheless provided here for completeness, and to provide a basis for comparing and contrasting the U.S. approach to other regulators who use the IAEA definitions.

\subsection{Literature Review}

\subsubsection{Overview of Guidance}

As indicated above, a large body of knowledge on nuclear power plant design and licensing has been developed over several decades. This development is ongoing and continually being refined. This applies especially to the vital process, not only of new plant design and construction, but to ensuring the longevity of the existing fleet of reactors.

New plants will by design employ advanced digital technologies and their engineering processes ensure that the total design for safe operation is well integrated. The integration process for plants that are being 
modified and modernized is different than new plants and very complex in many ways due to the required integration with existing systems and functions. The challenges for such projects include considerations like changes to licensing and design bases, engineering, financing, organization, operating procedures, human performance, concept of operations, and environmental issues. Some of these issues are extensively treated in regulatory and technical industry documentation, but some issue lag behind, due in some cases to the long hiatus in new plant development in the U.S.

The following is a summary of documents that address well-established guidance for new plants as well as modifications.

- $\quad$ NUREG-0800 - Standard Review Plan [15]

The standard review plan (SRP) provides guidance to NRC reviewers, but it also provides a source of guidance and understanding of NRC expectations related to I\&C and HSI upgrades. Of special importance to control room modernization is Chapter 7, which covers I\&C systems, and Chapter 18, which covers human factors and the HSI.

- $\quad$ NEI 01-01 / EPRI TR-102348 - Guideline on Licensing Digital Upgrades

This is the industry guideline on design and licensing of digital I\&C systems. It covers the overall I\&C upgrade design process, dealing with digital systems issues such as software common cause failure, diversity, and defense-in-depth. It specifically addresses digital issues in the context of 10 CFR 50.59 evaluations and how to determine the need for license amendments when making changes to the I\&C systems and HSIs. (Note this document will be superseded by EPRI 300200326).

- $\quad$ NUREG-0711 - Human Factors Engineering Program Review Model

This document describes the NRC expectations for a plant's human factors program and appropriate HFE design and evaluation processes. It addresses both new plant designs and modifications. This document is referenced by the SRP, NUREG-0800.

- NUREG-0700 - Human System Interface Design Review Guidelines [11]

As part of the NRC's review process, the interfaces between plant personnel and plant's systems and components are evaluated for conformance with HFE guidelines. The NUREG-0700 guidelines address the human factors aspects of the physical and functional characteristics of HSIs. In addition to the review of actual HSIs, the NRC can use the NUREG-0700 guidelines to evaluate a designspecific HFE guideline document or style guide.

\subsubsection{Applicable Codes, Standards, and Guidelines}

In addition to the regulatory documents reviewed above, there is also a substantial number of industry codes, standards, guidelines, and research reports that cover the human factors aspects of control room upgrades and associated licensing considerations. The following are considered the most prominent sources.

- IEEE 1023 - Recommended Practice for the Application of Human Factors Engineering to Systems, Equipment, and Facilities of Nuclear Power Generating Stations and Other Nuclear Facilities [6]

This standard addresses planning and application of human factors engineering in the design, operation, testing and maintenance of nuclear power plant facilities, systems, and equipment.

- INL/EXT-14-33223 - Baseline Human Factors and Ergonomics in Support of Control Room Modernization at Nuclear Power Plants [7]

This report describes baseline evaluations that can be done on current systems and HSIs prior to beginning the modernization program, providing baseline data on usability and human factors 
characteristics of the current systems so that the modernization can build on current strengths, and address any shortcomings in the present systems and control room HSIs.

- EPRI 3002004310 - Human Factors Guidance for Control Room and Digital Human-System Interface Design and Modification: Guidelines for Planning, Specification, Design, Licensing, Implementation, Training, Operation, and Maintenance for Operating Plants and New Builds

The guidance provided in this document is intended to help plant owner/operators, their suppliers, and their contractors to integrate HFE activities into their overall design efforts to ensure that the contributions of modern digital I\&C and HSI systems are realized. The document provides guidance and information that should be valuable for owner/operators and designers of new builds, and for owner/operators and designers of modifications for currently operating plants.

The document is especially important for operating plants because it provides practical guidance and examples for how HFE should be applied to the full range of plant modifications, from minor changes to large-scale control room modernization efforts, using a graded approach. It also describes how the site HFE program can be established or the existing program upgraded to reflect current industry and regulatory requirements and practices regarding application of HFE and use of digital I\&C and HSI technologies. 
THIS PAGE INTENTIONALLY BLANK 


\section{TREATMENT OF THE MODIFICATION PROCESS}

\subsection{Overview}

As indicated above, a substantial amount of guidance is currently available on all phases of the design, development, modification, and licensing of nuclear power plants. The purpose of such guidance is to support utilities, not only in the design of new plants, but also in the design and implementation of newer technologies, such as digital I\&C systems.

Since digital upgrades are proving to be especially challenging for all plants, a large amount of guidance is devoted to the regulatory aspects of plant modifications. This includes, for example, guidance on performing 10 CFR 50.59 evaluations and developing information to support LAR submittals. These guidelines present ways to address and resolve digital issues in the design and evaluation process, and they provide a road map to relevant standards and other sources of detailed guidance. However, they do not predetermine whether a LAR will be required for a particular type of digital upgrades; this task remains the responsibility of the licensee following the 10 CFR 50.59 process.

This modification task leads to two big challenges:

- The first big challenge for licensees is to understand the many applicable rules, regulations, guidelines, and standards pertaining to plant modifications and where they should be applied.

- The second challenge is to obtain, or develop, the expertise necessary to conduct the analyses for plant modifications. Utilities usually have easy access to most of the engineering disciplines involved in a modification.

One typical exception to the availability of engineering expertise is HFE. The main reason for this exception lies in the fact that modifications that do not affect human performance anywhere in the plant do not require human factors engineers. However, this is very different for modification of any structures, systems, and components (SSCs) that require human involvement in any location in the plant, whether in the main control room, local control station, during normal operations, maintenance, or emergency conditions. As utilities embark on large-scale modifications of outdated equipment, especially in control rooms, the inclusion of HFE in the overall engineering process is an additional challenge, because utilities do not typically have qualified human factors engineers on board. Also, most existing guidance documents provide only superficial guidance on how to develop an effective HFE program, how to perform the required HFE activities including methods and tools that can be used, and how to design, test and evaluate the needed HSIs. This makes deciding what associated design and analysis activities will meet the applicable regulatory requirements, guidelines, and standards even more challenging.

The following section describes the effect of modifications on the plant's licensing and design bases and how this will in turn determine the need for specialist expertise in handling license amendment requests used for control room modernization.

\subsection{The plant's design and licensing bases}

The NRC defines a plant's licensing basis as the set of NRC requirements that apply to a specific plant and a licensee's written commitments for ensuring compliance with and operation within applicable NRC requirements and the plant-specific design basis (including all modifications and additions to such commitments over the life of the license) that are documented and in effect.

The licensing basis is further comprised of selected information exchanged between a licensee and the NRC relating to design features, equipment descriptions, operating practices, site characteristics, programs and procedures, and other factors that describe a plant's design, construction, maintenance, and operation. Licensing basis information is contained in a variety of document types [e.g., final safety 
analysis report (FSAR), license amendments, etc.]. It also includes the plant-specific design-basis information defined in 10 CFR 50.2 as documented in the plant's most recent FSAR. Each licensing basis document has certain characteristics in terms of change control mechanisms, reporting of changes to the NRC, dealing with discrepancies, and the possible involvement of the public.

The plant's design basis is defined in 10 CFR 50.2 as the information that identifies the specific functions to be performed by a structure, system, or component of a facility, and the specific values chosen for controlling parameters as bounding references for design.

The licensee has primary responsibility for operating its plant safely and in compliance with its license. Since a plant's design and operation are not static, certain changes are necessary over the course of the facility's operating life. NEI 07-06 [12] states reactor licensees must follow NRC regulations to justify and implement changes in the design basis and licensing basis for their facilities.

\subsubsection{Determining the applicability with 10 CFR $\mathbf{5 0 . 5 9}$}

The threshold for screening out changes that do not require full evaluations under 10 CFR 50.59 have been clarified in recent years by the work of the NEI (e.g., NEI 96-07) and EPRI (3002004310). These guidelines help to conserve both licensee and NRC resources while continuing to ensure that significant changes are thoroughly evaluated and approved by the NRC as appropriate.

The licensee's FSAR, which describes all plant facilities and procedures, is the principal document on which the NRC bases its safety evaluation supporting the issuance of a facility operating license. Whenever modifications are made that affect the plant's licensing basis, an updated FSAR (UFSAR) must be submitted. The UFSAR incorporates changes made and serves as a major source of information on the current plant design and supporting analyses, and is considered part of the current licensing basis.

One important prerequisite for determining applicability of 50.59 therefore is that the UFSAR be maintained throughout the life of the plant.

After determining that a proposed activity is safe and effective through appropriate engineering and technical evaluations, the 10 CFR 50.59 process is applied to determine if a license amendment is required prior to implementation. NEI 96-07 describes three basic steps: (1) Applicability and Screening, (2) Evaluation, and (3) Documentation and Reporting.

This process is depicted in Figure 1: 


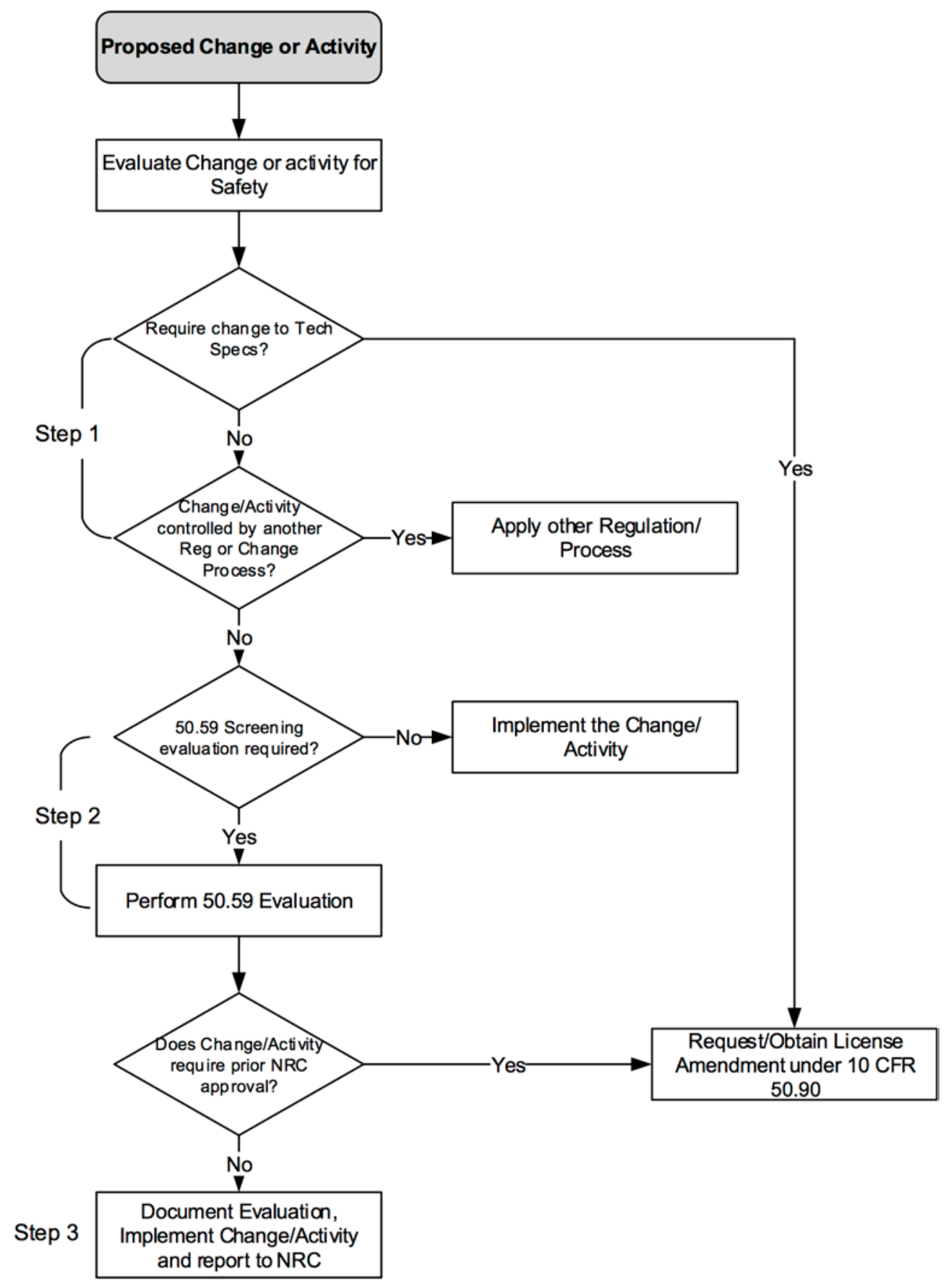

Figure 1: 10 CFR 50.59 Process (Adapted from NEI 96-07)

\section{Step 1: Applicability and Screening}

The screening process determines whether a proposed activity requires a 10 CFR 50.59 evaluation to be performed, prior to implementation.

10 CFR 50.59 applies to any changes, tests, or experiments not previously described in the licensee's UFSAR. This includes changes to technical specifications as well as any new requirements, for example control room modifications. 
Regarding changes that affect functions controlled by, or monitored by operators, NEI 96-07 states as follows:

"For purposes of 10 CFR 50.59 screening, changes that fundamentally alter (replace) the existing means of performing or controlling design functions should be conservatively treated as adverse and screened in. Such changes include replacement of automatic action by manual action (or vice versa), changes to the man-machine interface, changing a valve from "locked closed" to "administratively closed" and similar changes.” (NEI 96-07, Section 4.2.1.2).

It should be emphasized, however, that not all changes to the HSI would fundamentally alter the means of performing or controlling design functions. Some HSI changes that result from digital upgrades will leave the method of performing functions essentially unchanged, for example, where an analog control device on the control board is replaced with a digital equivalent on a distributed control system (DCS) display. Technical evaluations should determine whether such changes to the HSI create adverse effects on design functions (including adverse effects on the licensing basis and safety analyses).

In contrast, changes that could lead to potential adverse effects include, for example, changes to parameters monitors, changes that affect operator response times, changes from manual to automatic initiation, or changes that introduce potential new failure modes in operator-system interaction. Where such effects are screened in, a 50.59 evaluation will be required to determine if and how the modification might impact the method of performing or controlling a design function. This will include determining whether the modification could impact any human actions that are presently credited in the plant safety analysis as described in the FSAR, or if any new credited human actions will be added by the modification.

The screening process for important human actions described in EPRI 3002004310 explains how the identification of any important human actions associated with the modification will require assigning a high nuclear safety risk to the proposed activities. A high-risk level will require further analysis on a taskby-task basis to determine the level of HFE activities that need to be conducted for the modification.

This screening process and the determination of the level of HFE activities required is described in detail in EPRI 3002004310, Attachment A.

\section{Step 2: Evaluation}

The 10 CFR 50.59 evaluation is the documented evaluation against the eight criteria in 10 CFR 50.59(c)(2) to determine if a proposed change, test, or experiment requires prior NRC approval via license amendment.

This step requires evaluation of the eight threshold criteria to determine if a license amendment must be obtained from the NRC. These criteria determine whether the modification will result in, or create one or more of the following conditions:

(i) More than a minimal increase in the frequency of occurrence of an accident previously evaluated in the FSAR (as updated);

(ii) More than a minimal increase in the likelihood of occurrence of a malfunction of a SSC important to safety previously evaluated in the FSAR (as updated);

(iii) More than a minimal increase in the consequences of an accident previously evaluated in the FSAR (as updated);

(iv) More than a minimal increase in the consequences of a malfunction of an SSC important to safety previously evaluated in the FSAR (as updated);

(v) A possibility for an accident of a different type than any previously evaluated in the FSAR (as updated); 
(vi) A possibility for a malfunction of a SSC important to safety with a different result than any previously evaluated in the FSAR (as updated);

(vii) A design basis limit for a fission product barrier as described in the FSAR (as updated) being exceeded or altered; or

(viii) A departure from a method of evaluation described in the FSAR (as updated) used in establishing the design bases or in the safety analyses.

A positive response from the licensee to any of these conditions will require a LAR submitted to the NRC for prior approval if the licensee proposes to modify the license terms and conditions or the technical specifications, or if a proposed change, test, or experiment meets the criteria above.

LARs are governed by NRC regulations in 10 CFR 50.90-50.92. Procedures and guidance for development and review of license amendments are provided in Nuclear Reactor Regulation (NRR) Office Instruction LIC- 101, License Amendment Review Procedures. More specific guidance on this process may be found in NEI 07-06, which summarizes the nuclear regulatory process.

\section{Step 3: Documentation \& reporting}

Document and report to the NRC activities implemented under 10 CFR 50.59. This includes a report that describes the procedures, tests, and experiments associated with the modification, as well as the evaluation of each. In addition, the licensee is required to maintain records of all changes in the facility, including procedures, tests, and experiments associated with the modification for a period of five years.

Detailed descriptions of how 10 CFR 50.59 evaluations should be documented may be found in NEI 96 07, Section 5.

\subsubsection{Guidelines for Response to the 10 CFR 50.59 Screening Criteria}

The screening process for a modification starts with the evaluation of the impact on design functions as described in the plant's UFSAR. As described above, if there is no impact, the particular function is screened out of the 50.59 evaluation process and the change can be implemented. All other changes that do have an impact on the functions described in the UFSAR should be evaluated to determine if the change has an adverse effect. Changes with adverse effects are those that have the potential to increase the likelihood of malfunctions, increase consequences of a malfunction, or create new accidents.

Due to the relative lack of experience with large-scale digital upgrades, licensees often struggle to interpret the exact implications of the eight conditions described in the 50.59 screening criteria. The following table provides examples of typical considerations in the evaluation of the criteria.

Table 1: Considerations for 50.59 Evaluations

\begin{tabular}{|c|c|c|c|}
\hline \multicolumn{2}{|r|}{ 50.59 Criteria } & Evaluation Requirements & Result \\
\hline (i) & $\begin{array}{l}\text { Does the activity result in more } \\
\text { than a minimal increase in the } \\
\text { frequency of occurrence of an } \\
\text { accident? }\end{array}$ & $\begin{array}{l}\text { This requires an engineering } \\
\text { evaluation of the quality, reliability } \\
\text { and qualification of the system. } \\
\text { Specific attention must be paid to } \\
\text { automation of a function that could } \\
\text { relate to an initiating event, increase } \\
\text { the need for operator intervention, or } \\
\text { increase the probability of an } \\
\text { accident [based on probabilistic risk } \\
\text { assessment (PRA) calculations]. }\end{array}$ & $\begin{array}{l}\text { A digital upgrade would not be } \\
\text { expected to result in more than } \\
\text { a minimal increase in the } \\
\text { frequency of accident } \\
\text { occurrence. Any change is } \\
\text { considered to have a negligible } \\
\text { effect when the change is very } \\
\text { small or it is too difficult to } \\
\text { determine if a change has } \\
\text { actually occurred. }\end{array}$ \\
\hline (ii) & $\begin{array}{l}\text { Does the activity result in more } \\
\text { than a minimal increase in the }\end{array}$ & $\begin{array}{l}\text { This requires an engineering } \\
\text { evaluation such as failure modes and }\end{array}$ & $\begin{array}{l}\text { As with criterion (i), a digital } \\
\text { upgrade would be considered to }\end{array}$ \\
\hline
\end{tabular}




\begin{tabular}{|c|c|c|c|}
\hline & 50.59 Criteria & Evaluation Requirements & Result \\
\hline & $\begin{array}{l}\text { likelihood of occurrence of a } \\
\text { malfunction of an SSC } \\
\text { important to safety? }\end{array}$ & $\begin{array}{l}\text { effects analysis (FMEA) to determine } \\
\text { if the change can cause an increase in } \\
\text { the probability of SSC failure. } \\
\text { Specific attention must be paid to the } \\
\text { difference in failure rate between old } \\
\text { analog equipment and new digital } \\
\text { hardware and software. }\end{array}$ & $\begin{array}{l}\text { have a negligible effect when } \\
\text { the change is very small or it is } \\
\text { too difficult to determine if a } \\
\text { change has actually occurred. } \\
\text { Digital hardware is typically } \\
\text { more reliable than the } \\
\text { equipment it replaces and where } \\
\text { sufficient operating and testing } \\
\text { history exists, licensees can } \\
\text { credit system features like fault } \\
\text { tolerance and self-diagnosis and } \\
\text { self-correction in the evaluation. }\end{array}$ \\
\hline (iii) & $\begin{array}{l}\text { Does the activity result in more } \\
\text { than a minimal increase in the } \\
\text { consequences of an accident? }\end{array}$ & $\begin{array}{l}\text { Evaluation of this criterion requires } \\
\text { determining if the modification } \\
\text { would lead to an increase in potential } \\
\text { radiological dose from an accident. }\end{array}$ & $\begin{array}{l}\text { If the system in question does } \\
\text { not directly contribute to } \\
\text { accident prevention or } \\
\text { mitigation, then a digital } \\
\text { upgrade to the system will not } \\
\text { likely increase the consequences } \\
\text { of an accident and the change } \\
\text { can be implemented without } \\
\text { prior NRC approval. }\end{array}$ \\
\hline (iv) & $\begin{array}{l}\text { Does the activity result in more } \\
\text { than a minimal increase in the } \\
\text { consequences of a } \\
\text { malfunction? }\end{array}$ & $\begin{array}{l}\text { This criterion should be evaluated in } \\
\text { conjunction with criterion (vi), which } \\
\text { will show if the change introduces } \\
\text { any malfunctions not previously } \\
\text { analyzed in the UFSAR. Further } \\
\text { analysis is required to determine if } \\
\text { the system plays a role in mitigating } \\
\text { the radiological consequences of an } \\
\text { accident, and if the change might be } \\
\text { detrimental to that mitigating } \\
\text { function. }\end{array}$ & $\begin{array}{l}\text { As with criterion (iii), if the } \\
\text { system in question does not } \\
\text { directly contribute to accident } \\
\text { prevention or mitigation, then a } \\
\text { digital upgrade to the system } \\
\text { will not likely increase the } \\
\text { consequences of an accident and } \\
\text { the change can be implemented } \\
\text { without prior NRC approval. }\end{array}$ \\
\hline (v) & $\begin{array}{l}\text { Does the activity create a } \\
\text { possibility for an accident of a } \\
\text { different type? }\end{array}$ & $\begin{array}{l}\text { Evaluation of this criterion requires } \\
\text { determining if the modification could } \\
\text { create new events that differ from the } \\
\text { types of accidents evaluated in the } \\
\text { UFSAR. Specific attention must be } \\
\text { paid to the identification of new } \\
\text { credible failure modes that differ } \\
\text { from the existing equipment. }\end{array}$ & $\begin{array}{l}\text { If there is reasonable assurance } \\
\text { that the likelihood of different } \\
\text { type of accident due to an I\&C } \\
\text { upgrade is sufficiently low, then } \\
\text { the upgrade would not require } \\
\text { prior NRC approval. }\end{array}$ \\
\hline (vi) & $\begin{array}{l}\text { Does the activity create a } \\
\text { possibility for a malfunction of } \\
\text { an SSC important to safety } \\
\text { with a different result? }\end{array}$ & $\begin{array}{l}\text { Evaluation of this criterion requires } \\
\text { engineering analyses of the results of } \\
\text { potential failures of the modified } \\
\text { system. Specific attention must be } \\
\text { paid to: } \\
\text { - Analysis of failures (e.g. } \\
\text { software common cause failures) } \\
\text { to identify results different from } \\
\text { those analyzed in the UFSAR. } \\
\text { - Analysis of effects of a digital } \\
\text { upgrade that could create new } \\
\text { results of malfunctions (e.g. as a }\end{array}$ & $\begin{array}{l}\text { If there is reasonable assurance } \\
\text { that the likelihood of failure due } \\
\text { to software is sufficiently low, } \\
\text { then the upgrade would not } \\
\text { require prior NRC approval on } \\
\text { the basis of software common } \\
\text { cause failures. Digital upgrades } \\
\text { of non-safety systems in the } \\
\text { control room are typically } \\
\text { screened out if the licensee's } \\
\text { evaluation shows no difference, } \\
\text { or an improvement in operator } \\
\text { performance (e.g. replacement }\end{array}$ \\
\hline
\end{tabular}




\begin{tabular}{|c|c|c|c|}
\hline \multicolumn{2}{|r|}{ 50.59 Criteria } & Evaluation Requirements & Result \\
\hline & & $\begin{array}{l}\text { result of combined functions, } \\
\text { new system interactions, } \\
\text { different response times, etc.) } \\
\text { Analysis of effects of new ways } \\
\text { of presenting information and } \\
\text { controlling functions in the } \\
\text { control room } \\
\text { Analysis of all human factors } \\
\text { issues related to the modification }\end{array}$ & $\begin{array}{l}\text { of a strip chart recorder with a } \\
\text { digital trend display with the } \\
\text { same data in the same location). } \\
\text { However, failures that could } \\
\text { result from the following will } \\
\text { require } 50.59 \text { evaluation and } \\
\text { possible license amendment: } \\
\text { - human error (e.g., mis- } \\
\text { operation of an HSI, or } \\
\text { failure to detect a condition } \\
\text { due to a change in } \\
\text { displayed information or an } \\
\text { automated function that } \\
\text { alters operator response to a } \\
\text { transient), or } \\
\text { unauthorized entries or } \\
\text { system changes that could } \\
\text { affect the function of an } \\
\text { important system in a way } \\
\text { not previously analyzed in } \\
\text { the UFSAR }\end{array}$ \\
\hline (vii) & $\begin{array}{l}\text { Does the activity result in a } \\
\text { design basis limit for a fission } \\
\text { product barrier being exceeded } \\
\text { or altered? }\end{array}$ & $\begin{array}{l}\text { Evaluation of this criterion requires } \\
\text { determining of any change in the } \\
\text { controlling numerical values of fuel } \\
\text { cladding, reactor coolant system } \\
\text { boundary, and containment, as } \\
\text { analyzed in the UFSAR. Special } \\
\text { attention must be paid to differences } \\
\text { in response or processing time } \\
\text { between existing analog devices and } \\
\text { the digital upgrade. }\end{array}$ & $\begin{array}{l}\text { This type of digital modification } \\
\text { is not likely to affect operator } \\
\text { performance. However, if the } \\
\text { change would result in the } \\
\text { design basis limit for the } \\
\text { parameter being exceeded, then } \\
\text { the change would not be } \\
\text { implemented under } 10 \text { CFR } \\
50.59 \text { and would require prior } \\
\text { approval by the NRC. Similarly, } \\
\text { if the change includes alteration } \\
\text { of the numerical value of the } \\
\text { design basis limit and a } \\
\text { corresponding display change in } \\
\text { the control room, NRC review } \\
\text { and approval would be required. }\end{array}$ \\
\hline (viii) & $\begin{array}{l}\text { Does the activity result in a } \\
\text { departure from a method of } \\
\text { evaluation described in the } \\
\text { UFSAR used in establishing } \\
\text { the design bases or in the safety } \\
\text { analyses? }\end{array}$ & $\begin{array}{l}\text { The emphasis in this criterion is to } \\
\text { determine if there will be any change } \\
\text { in evaluation methods for safety } \\
\text { analysis or design basis. }\end{array}$ & $\begin{array}{l}\text { The licensee would obtain NRC } \\
\text { approval for changes to the } \\
\text { analytical methods separately } \\
\text { from implementing physical } \\
\text { plant changes. It is therefore } \\
\text { unlikely that a digital upgrade } \\
\text { would involve a departure from } \\
\text { a method of evaluation. }\end{array}$ \\
\hline
\end{tabular}

\subsubsection{Treatment of License Amendment Requests}

When the results of the 50.59 evaluation described above indicate the need for a LAR, a submittal will be prepared that typically includes the following:

- A summary of the proposed change and technical justification; 
- The proposed revision to the Technical Specifications and Bases, if applicable;

- The proposed revision to the UFSAR, if applicable;

- Discussion of the determination that the amendment request contains no significant hazard considerations; and

- Discussion of any environmental considerations

In addition to the mandatory content of the LAR, the regulator might require additional documentation (for example, a White Paper) on the nature of a digital upgrade and how this impacts the plant's overall defense-in-depth and diversity.

Decision making associated with plant modifications is complex and up-to-date guidance can help to reduce risk. The plant's licensing basis requires certain personnel to have a broad range of technical expertise and competence in plant issues and the LAR process may require them to review a number of different types of plant issues and provide a recommendation to the plant manager on the advisability of recommended actions.

\subsection{General Licensing Considerations for Modifications}

The design and acceptance of digital systems with modern HSIs remain a significant challenge for the nuclear industry. However, the NRC has developed approaches and guidance for regulatory review and acceptance of the new technologies. HSI modernization is addressed in the NRC guidance - recent revisions to Chapter 18 of NUREG-0800 and NUREG-0711 address modernization of existing plant control rooms and HSIs in addition to new designs. Also, modern digital interfaces are covered in the recent revision to the NRC's detailed HSI review guidelines, NUREG 0700.

A strategy that many plants have adopted is to make changes first to non-safety systems - this allows an opportunity to ensure that the necessary processes are in place and to gain experience with the processes and the newer digital technologies before making changes to the safety systems, which carry higher licensing risk. It also allows plants a low-risk way of evaluating how well the new digital I\&C and HSI hardware and software works for their crews.

Developing a HFE program at the planning, stage as shown in Figure 2.4-1 in EPRI 3002004310, ensures that it is compliant with the expectations of NUREG-0711. This mechanism of obtaining NRC review of the program at the earliest opportunity can reduce the amount of licensing effort and risk associated with the downstream modifications. Also, an early look at potential 10 CFR 50.59 issues associated with changes that will affect operator performance can help minimize licensing risk.

A further licensing risk is determining what HSIs will be needed to supplement DCS workstations, including qualified HSIs and what design requirements apply to them. It is important to address this early in the program because it will also impact the overall control room design project, and therefore plant operations.

More guidance on regulatory and licensing activities during a modification project is available in Chapter 5 of EPRI 3002004310, NEI 01-01, NEI 96-07, and NEI 07-06.

\subsection{Management of the HFE Aspects of Modifications}

\subsubsection{Human Factors Engineering inputs to 10 CFR 50.59}

It is a well-known fact that there are significant challenges involved in the design and acceptance of digital systems for modern HSIs and advanced control room designs. To cope with this, the NRC and the nuclear industry have developed approaches and guidance for regulatory review and acceptance of the new technologies. Regulatory review of the human factors aspects of plant design and modifications has 
been firmly established in various regulations since NUREG-0737, “Clarification of Three Mile Island (TMI) Action Plan Requirements” [17], was issued after the TMI II accident in 1979. Guidance for control room and HSI design has evolved significantly over the past four decades.

The increasing trend to modernize control rooms with advanced I\&C and HSI technology as part of projects to extend the operating life of older nuclear power plant is making this guidance more important than ever. At the same time there is increasing regulatory scrutiny of licensee's modernization plans. Modern HSIs are already being reviewed as part of license application for new plant designs, but this remains a challenge for utilities that are embarking on large-scale modifications of outdated equipment.

Changes that impact human performance, such as changes to the level of plant automation, changes to personnel tasks, and changes to HSIs or control rooms are like any other plant modification - they are governed by 10 CFR 50.59. As described before, this regulation allows licensees to determine whether a change requires a license amendment and prior NRC review and approval, or if the change can be implemented within the current licensing basis (no license amendment and no prior review required). Plants are expected to follow a modification program that includes application of appropriate HFE principles and processes, and to use 10 CFR 50.59 and other supporting standards and guidance to determine when NRC review of a change is required.

A 10 CFR 50.59 evaluation is typically performed for the overall modification, including both I\&C and HFE aspects. It should be expected that significant HSI changes will screen in (i.e., require a 50.59 evaluation), but the evaluations may conclude that the modifications do not require prior review and approval. It is the general expectation that individual changes to the HSI made as part of modernization will be designed such that they improve human performance. Such changes will usually not increase the probability or consequences of accidents or malfunctions, nor create new accidents or malfunctions with different results. However, some HSI changes could require a license amendment if they present the possibility of new malfunctions not previously analyzed. Such malfunctions may be associated with new I\&C that could potentially introduce new failure modes. The failure analysis performed for the modification should therefore include consideration of plausible HSI failures and potential human errors or commission and errors of omission associated with use of the new HSI. In either case it is important to document the bases for such judgments as part of the 50.59 evaluation. HFE analyses and evaluations in terms of NUREG-0711 provide the basis for these types of judgments.

Figure 2 is a high-level representation of how the 10 CFR 50.59 evaluation applies to the whole modification, including both I\&C and HFE aspects. The diagram, which has been adapted from NEI 0101 and NEI 97-07, illustrates a process that evaluates the human factors in parallel with the engineering aspects of the digital I\&C upgrade. All activities associated with a modification start with an identification of functions affected by an I\&C upgrade, but the development of a HFE program plan can start at the same time. 


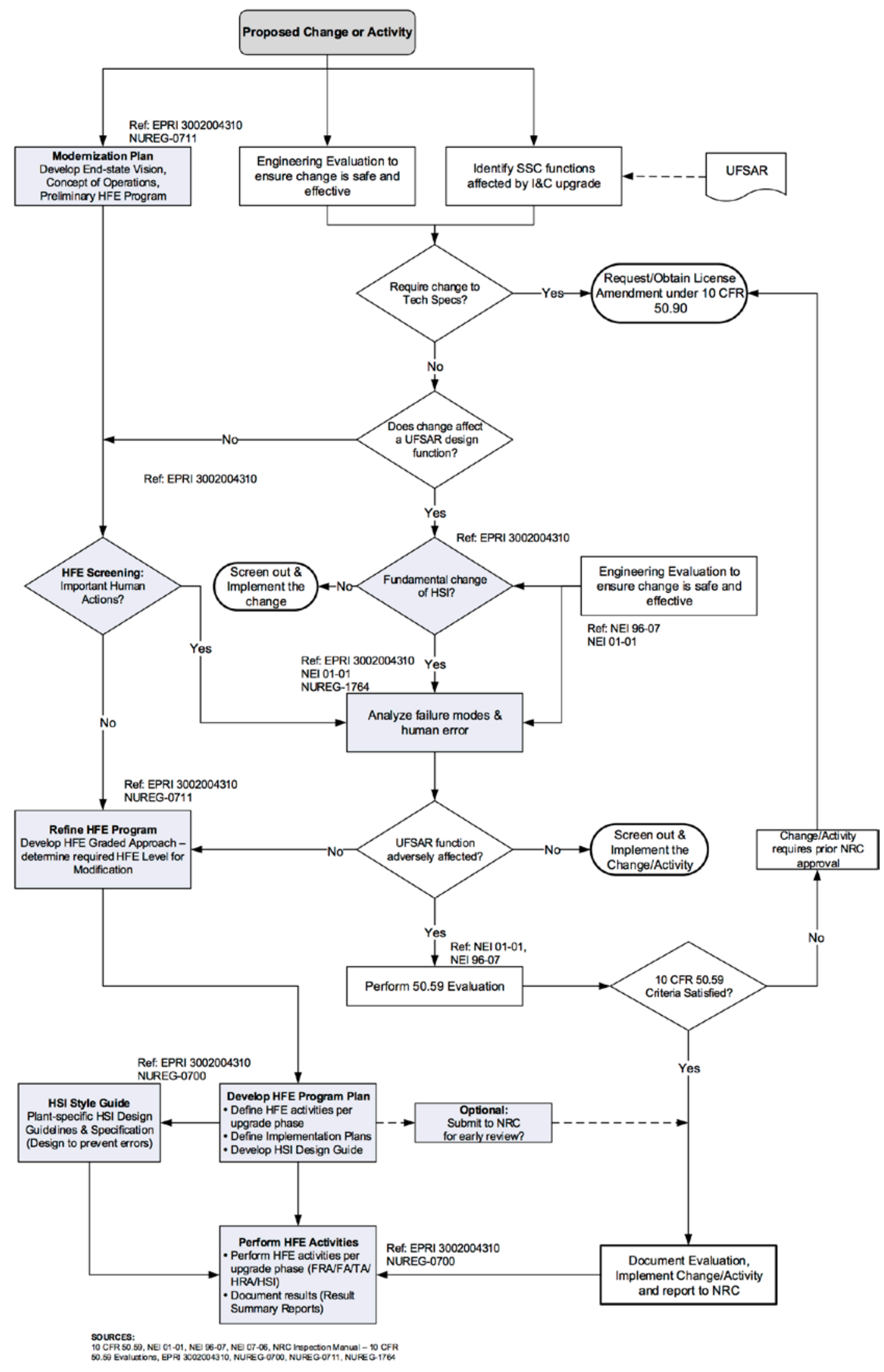

Figure 2: Human Factors Aspects of the 50.59 Evaluation Process 
The principal concern related to the design and functioning of the HSI is the possibility of system failure due to human error, or due to unauthorized entries or alterations of the system through a maintenance, test, or configuration interface. Administrative controls, security, appropriate training, and plant procedures may be provided to minimize the possibility of such events. However, the first consideration in the design or selection of a new HSI must always be to prevent human error in the first place. This may be achieved through a thorough understanding of potential failures of both human and system and then designing an error-tolerant HSI that has the following characteristics:

- It does not unduly penalize human error and makes it very difficult for the operator to perform an incorrect action, for example by means of behavior-shaping constraints or forcing functions

- It allows equipment to continue functioning in the presence of hardware faults

- It mitigates or limits the effects of errors after they have been made, by means of effective recovery mechanisms

As indicated in Figure 2 where modifications are considered, engineering evaluations must determine whether changes to the HSI will create adverse effects on design functions (including adverse effects on the licensing basis and safety analyses). HSI changes that could lead to potential adverse effects include, for example (see NEI 01-01, Section 4.3.4):

- Changes to parameters monitored, decisions made, and actions taken in the control of plant equipment and systems during transients;

- Changes that could affect the overall response time of the human/machine system (e.g., changes that increase operator burden);

- Changes from manual to automatic initiation (or vice versa) of functions;

- Fundamental changes in data presentation (such as replacing an analog gauge with a digital indicator on a visual display unit (VDU) where access to the data requires operator interactions to display the indicator), or

- Changes that create new potential failure modes in the interaction of operators with the system, such as new interrelationships or interdependencies of operator actions and plant response, or new ways the operator assimilates plant status information as a result of changes in situation awareness.

Extensive HFE analyses may therefore result from the findings of the technical evaluation that:

- Important human actions are involved in the modification;

- The modification will fundamentally change the HSI; or

- The modification might result in opportunities for new failure modes.

Such HFE analyses may include, for example, human reliability analysis (HRA), workload analysis, cognitive work analysis, or physical ergonomics analysis.

Ideally these analyses should be conducted in an environment with high ecological validity (that is, an environment where the methods, materials and setting of the analysis closely match the actual operational environment like the plant's main control room or training simulator). Such an environment is offered, for example, by INL's Human System Simulation Laboratory (HSSL). This facility allows intensive evaluation and testing on the new equipment before it is installed at the plant, while also enabling operators to familiarize themselves with the existing equipment.

Where such analyses are conducted by qualified personnel using human factors verification and validation $(\mathrm{V} \& \mathrm{~V})$ techniques, the results should be credited for minimizing the likelihood of human errors and inadvertently introducing a new behavior or problem that did not previously exist for the old device. 
However, as stated in NEI 01-01 (Section 4.3.4), not all changes to the human-system interface will fundamentally alter the means of performing or controlling design functions. Some HSI changes that are involved in digital I\&C upgrades will leave the method of performing functions essentially unchanged and it may then be reasonable to conclude that the design function is not adversely affected.

\subsubsection{Applying Human Factors Impact Screening Criteria}

As shown in Figure 2, the 50.59 evaluation process includes determining the impact of the planned modification on human performance and plant safety. Once it has been determined which functions are affected, a method is required to determine what disciplines, programs, and stakeholders are impacted or need to be involved in the modification.

The screening process aims to identify the modifications that clearly have HFE impact because they add, change, or replace an existing function or HSI. The screening criteria applied to determine the impact of the modification on human and system performance should be consistent with the intended scope of the plant's modernization project. Particular emphasis is placed on operator tasks and the ability to perform them safely and effectively. Attention is also paid to workspace environmental factors like lighting and noise, workspace arrangement, etc. The application of the criteria will determine which parts of the HFE program and associated procedures are invoked, and whether site HFE personnel will need to be involved in the modification.

Changes that "screen in" as described before include those that impact operator HSIs inside or outside the main control room (MCR), or changes to workplaces where operators use HSIs. Changes that do not modify HSIs but could have other potential impacts on operator tasks are also included, e.g., system changes that reduce the amount of time available for an operator to perform a task.

Changes that have potential HFE impact can vary widely in scope and extent of change, complexity, safety significance and importance to plant operation. For example, changes to operator HSIs can range from replacing an analog meter with a digital one, or a minor change to an existing computer display, to an entire system replacement involving conversion of analog displays and controls to computer-based workstations.

\subsubsection{Example: Treatment of the 10 CFR 50.59 evaluation}

To illustrate the role and impact of regulatory considerations on modification strategies, this section describes two hypothetical licensing basis reviews of human factors impacts performed at a generic pressurized water reactor (PWR) ${ }^{1}$. The first review does not result in a license amendment, the second one does. Both examples have been simplified to illustrate only the essential impacts on the licensing and design bases and subsequent need for human factors intervention.

\subsubsection{Evaluation Scenario 1: Replacement of Rod Position Indication System}

- Activity description

The existing Rod Position Indication (RPI) system provides indication of actual and demanded control rod positions. In addition, the system provides alarms to alert the reactor operator to misaligned rods, or to the fact that the required shutdown margin is not available due to excessive rod insertion. The indicators on the control board in the control room consists of a set of electromechanical numeric indicators providing the actual position of all rods in terms of steps withdrawn from the bottom of the core.

\footnotetext{
${ }^{1}$ Parts of these hypothetical licensing examples comes from: ML13101A369, which discusses aspects of the Renewed Facility Operating License for H.B. Robinson Unit 2, and NEI 96-07.
} 
The replacement and testing activities involve replacing the degraded, analog RPI system with a Digital Rod Position Indication (DRPI) system that offers high efficiency and reliability. This includes replacing the DPI control system as well as all indicators on the control board. The new DRPI is less susceptible to degradation due to electro-mechanical failures than the previous unit and will also provide the operators easier monitoring and detection of rod positions.

The indication scheme of the new DRPI will consist of a visual display panel that features a vertical bar graph for each rod that represents the position of the rod from the bottom of the core. Each bar will also show the numerical step value of the rod. This arrangement facilitates the visual detection of rod deviations as well as easy visual comparison of position between rods. Displayed beneath each rod position indicator is also the associated rod bottom light.

To reduce the impact of the modification on plant operations, the upgrade strategy is to replace the entire system during a scheduled plant refueling outage.

- Summary of Evaluation

The evaluation (using the Human Factors Impact Screening Checklist F-01 in EPRI 3002004310) indicated that the digital modification will change HSIs used by operators. In addition, it was found that the modified HSI is likely to have a very beneficial effect on the operators' ability to monitor rod positions and quickly detect any anomalies. This is ascribed to the fact that the display will be mounted on a vertical section of the control boards that will make it easier to observe from a distance than the existing discrete indicators that are mounted on the apron section of the control board, which requires operators to stand at the board to be able to read the values.

The further assessment to determine the potential risks (using the HFE Graded Approach Checklist F-02 in EPRI 3002004310) indicated that a low risk level was assigned to nuclear safety and economic operation. In addition, an examination of the task, including FMEA and Human-Hazard and Operability (HAZOP), determined the following:

- $\quad$ No Important Human Actions are involved

- The task as well as the HSI are low complexity and low frequency, and the modification should result in a significant simplification, due to improved situation awareness and easy detection.

- The uncertainty associated with the change is very low

- $\quad$ No new failure modes have been identified and existing ones (e.g. failure of a step counter) have been eliminated.

- Conclusion of the evaluation

It was concluded that the new system has been developed in accordance with a well-defined lifecycle process that complies with industry standards and regulatory guidance. In addition, based on the simplicity of the new system, its operating history in other plants, and expected improvement of operator performance, it was concluded that no adverse effects are created and therefore the modification satisfied all 50.59 criteria and did not require prior NRC approval. The modification can proceed as planned.

\subsubsection{Evaluation Scenario 2: Turbine Control System Replacement}

\section{- Activity Description}

The replacement and testing activities involve replacing the degraded, analog Turbine Control System (TCS) with a new digital TCS that offers higher efficiency and reliability, compared to the existing analog control system. The new TCS is less susceptible to degradation due to electromechanical failures than the previous unit. The TCS replacement comprises an extensive digital upgrade that includes migration of analog I\&C to digital equivalents that utilize a DCS. 
Since the TCS replacement forms part of the licensee’s long-term strategy to upgrade the control rooms, this activity is expected to affect modification to certain other plant SSCs.

The existing hard controls and indicators will be replaced by DCS-based information and controls on touch screens that provide soft control capability. These displays will allow operators to access a number of display pages for monitoring, control, and diagnostic functions.

It is expected that the new HSI will improve overall system reliability as well as operator performance. This will be achieved through reduced complexity, concentration of all indications and controls in a smaller display space, elimination of the need to find multiple indications and controls in multiple locations, and integration of cautions and warnings in the displays to prevent potential errors.

To reduce the short-term impact of the modification on plant operations, the upgrade strategy is phased over a number of years, with each phase defined in terms of graded I\&C and HFE activities that define the permissible design features and plant operator modification for each phase, in accordance with NUREG-0711.

- Summary of Evaluation

Although the modification is expected to result in an overall improvement in system reliability, a number of potential adverse effects have been identified:

- The most significant effect appeared to be the fundamental change in the interaction modality introduced by the digital HSI. That is, instead of manually manipulating hard controls (switches, buttons and J-handles) and reading discrete values on analog meters and gauges, the new HSI requires the operator to perform monitoring and control actions on touch screens where multiple display pages must be accessed.

- The cognitive complexity of some aspects of the task appeared to be higher, due to the increased time to perform some control actions, and the need to remember and call up specific display screens to find a required soft control.

- Because of the change in interaction modality and the change in location of indicators and controls from the control board to flat panel displays, the TCS procedures must be updated.

- Conclusion of the evaluation

It was concluded that the HSI for the updated TCS has been developed using a valid HFE approach, with verification and validation consistent with current industry and regulatory standards and guidelines. However, because of the potential adverse effects and procedure changes, the change is conservatively screened in and will undergo a 10 CFR 50.59 evaluation.

\subsection{The Human Factors Engineering Program Plan}

As indicated before, certain modification will inevitably include human factors impacts. NEI 96-07 provides guidance on performing the 10 CFR 50.59 evaluations, and NEI 01-01 provides guidance on the treatment of HSI changes and use of human factors input in 10 CFR 50.59 screenings and evaluations for digital I\&C changes, and it provides some examples that illustrate this. In addition, following NUREG0711 and NUREG-0700 is considered mandatory for modifications that affect any human interaction with plant and systems. The proposed HFE-related changes, tests, and experiments must be described in the licensee's Human Factors Engineering Program Plan (HFEPP), which would ensure that appropriate HFE input is provided to 10 CFR 50.59 screening and evaluation when required for a modification. The results of HFE activities for a modification conducted in accordance with NUREG-0711 will provide information to support any reviews by the NRC and for license amendments if required.

The integration of HFE into the overall engineering project will enable early and consistent input of HFE requirements into system design specifications and automation decisions as a matter of policy, thereby 
ensuring that the design never dictates the human task. This process will also ensure that the plant's goals for the control room modernization will be achieved by following a process that includes review of inputs, system documentation, functional, and human requirements, work verification, procurement and HSI design follow-up, and acceptance testing. Provision will also be made in all processes for necessary iteration, review, and verification.

The need for a comprehensive, site-specific HFEPP is defined clearly in NUREG-0711. In fact, the use of the HFEPP to identify and perform needed HFE activities can be credited as one of the means by which the modification engineering process helps ensure that human performance is maintained or enhanced and not degraded as changes are made. This can be of help, not only in answering the screening and evaluation questions of 10 CFR 50.59, but will ensure that the nuclear industry can move beyond mere obsolescence management and towards a unified, systematic, and long-term strategy to control room modernization. Such a rigorous approach will ensure that the industry will avoid the step-wise, like-forlike, piecemeal, non-integrated, approach to control room upgrades.

As noted in the examples above, applying an HFE program for modifications that follows the guidelines in NUREG- 0711 and NUREG-0700, will help to ensure that the plant's existing licensing basis commitments will continue to be met as the modifications are made. Also, it is important to note that following such a program, and implementing appropriate HFE activities for plant modifications, reflects good engineering practice and helps ensure continued plant safety, operability, reliability, and maintainability in addition to meeting regulatory commitments.

The purpose of the HFEPP for control room modernization can therefore be defined as follows:

1. It provides a practical, easy-to-use source of HFE information, oriented to the needs of the modernization project as well as all future modifications;

2. It provides a systematic method for integrating human factors principles and methods into control room HSI analysis, design, evaluation, and implementation to achieve safe, efficient, and reliable operation, maintenance, testing, inspection, and surveillance of the modified control room SSC;

3. The plan specifies HFE activities and design processes that will result in effective HSI designs that can be consistently and safely operated and maintained, and which are compatible with human information requirements, capabilities and limitations;

4. It specifies HFE activities and design processes that, in conjunction with the use of a HSI Style Guide and HSI Specifications, will result in effective HSI designs that can be consistently and safely operated and maintained, and that are compatible with human capabilities and limitations, as well as information and performance requirements;

5. It identifies relevant design information and design inputs necessary to aid the development of plantspecific designs and subsequent operational practices required by the plant;

6. It helps to ensure that human factors considerations are addressed, resolved and documented throughout all stages of system definition, design, development, verification and validation;

7. It establishes the responsibility for incorporating and coordinating human factors considerations in all control room and HSI analysis, design and modification activities;

8. It assigns HFE activities a level of priority equal to that of other system design engineering activities;

9. It serves as a basis for communication on human factors issues at all levels of the organization;

10. It establishes mechanisms and infrastructures to support all groups and individuals involved in the control room modernization project.

The integration of HFE with the plant's modernization project specifically with other engineering disciplines will result in the necessary interactions between human factors specialists and system 
engineers during system design and development. This includes integration of all requirements and resolving potentially conflicting requirements submitted by different engineering disciplines, which could include those from the human factors engineer, whose primary focus is on the design of the interaction between humans and systems.

The process through which the project team executes its responsibilities should be established in project policies that also address the requirements of 10 CFR 50.59 and NUREG-0711.

The HFE process includes the twelve technical elements outlined in NUREG-0711 as shown in Figure 3:

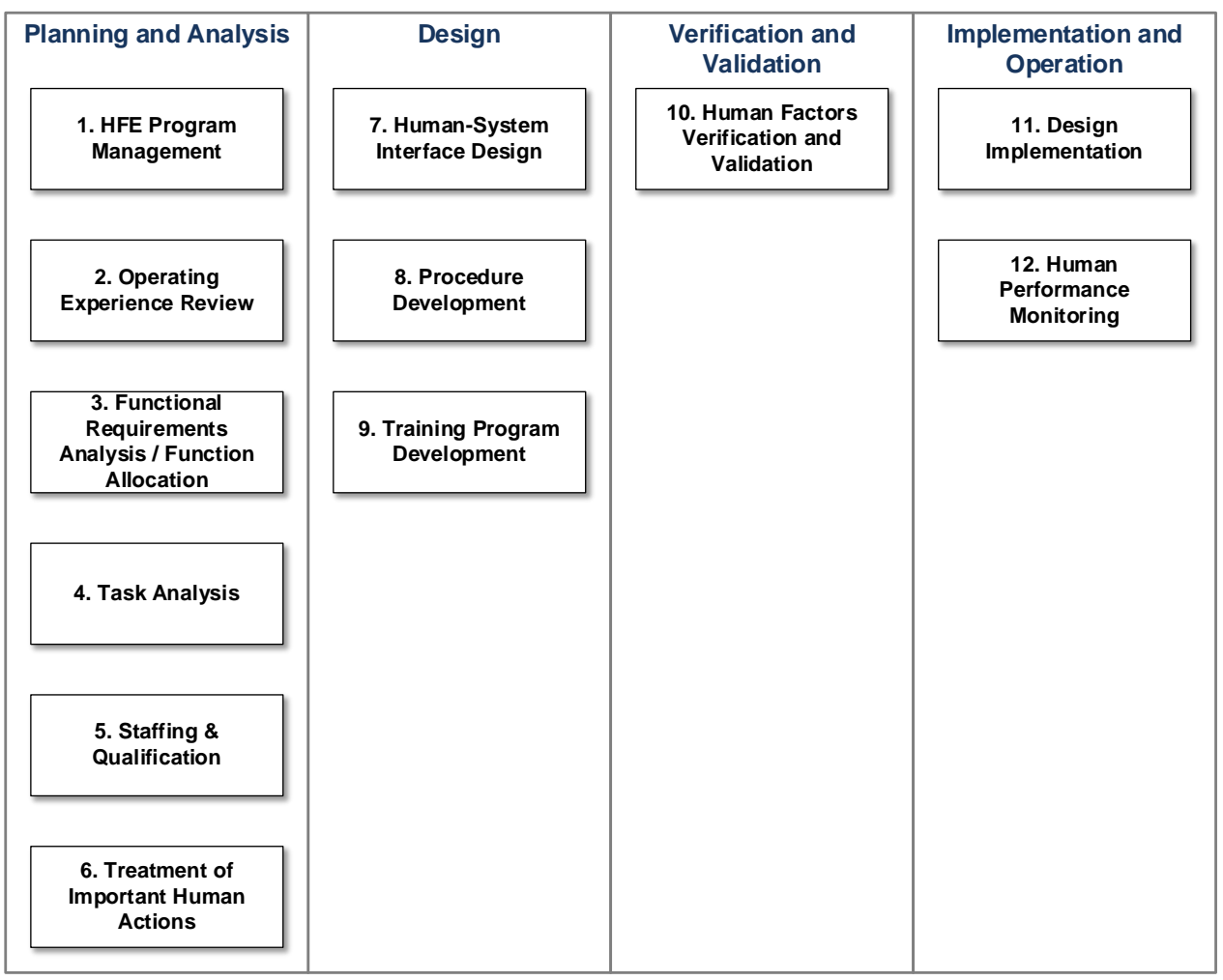

Figure 3: HFE Elements described in NUREG-0711, Rev 3

It should be noted that NUREG-0711 is neither a standard nor a process; it is primarily intended to serve as guidance for NRC staff in the review of a license applicant's HFE program. However, it has become so well established as guidance in the nuclear industry world-wide, that it forms a very useful basis for HFE efforts in any new design or modification. As a regulatory document, it accurately describes why the organization should conduct HFE and how such activities will be reviewed by the regulator, if and when it becomes necessary to conduct a license amendment review. Also, because there is more international experience with the implementation of this guideline than with any other comparable document, it is very beneficial to adopt it as a framework within which the plant can conduct its HFE activities.

As a rigorous framework for the HFEPP, NUREG-0711 can also serve as the basis for generic criteria for HFE practices and guidelines that would be incorporated into the control room modernization project. The following principles, typically described in the plant's HFEPP, will provide a structured and systematic approach to the analysis, design and evaluation of HFE aspects of the system upgrades:

1. HFE is integrated into the design, development and evaluation of all modified SSC.

2. Operating experience review (OER) is conducted to identify HFE-related safety issues. 
3. Functional requirements analysis and function allocation analysis is conducted to verify that the plant's functional requirements and function allocations take advantage of human strengths and avoid allocating functions that would be negatively affected by human limitations.

4. Task analysis is conducted to identify the functional, technical, knowledge, and skill requirements of the tasks that plant personnel must perform.

5. The HSI design method translates functional and task requirements to the detailed design of displays, controls, alarms, and other aspects of the HSI.

6. HFE principles and guidance are provided to specialists to develop operating procedures that are technically accurate, comprehensive, explicit, easy to use, and validated.

7. HFE principles and guidance are provided to training specialists to update the training program, where necessary, based on the systematic analysis of task requirements.

8. Human Factors V\&V is conducted to determine that the design conforms to HFE design principles, and enables personnel to successfully and safely perform their tasks to achieve operational goals.

9. HFE Design Implementation verifies that the as-built design conforms to the verified and validated design that resulted from the HFE design process.

10. A Human Performance Monitoring strategy exists to ensure that no functional or safety degradation occurs because of any changes that are made in the plant and to verify that the conclusions that have been drawn from the evaluation remain valid over time.

The application of these elements in an engineering project results in a non-linear flow of activities, with various interdependencies. Figure 4 below represents the generic flow and the several iterations of HFE and engineering activities in the modernization of an existing control room, or development of a new control room. 


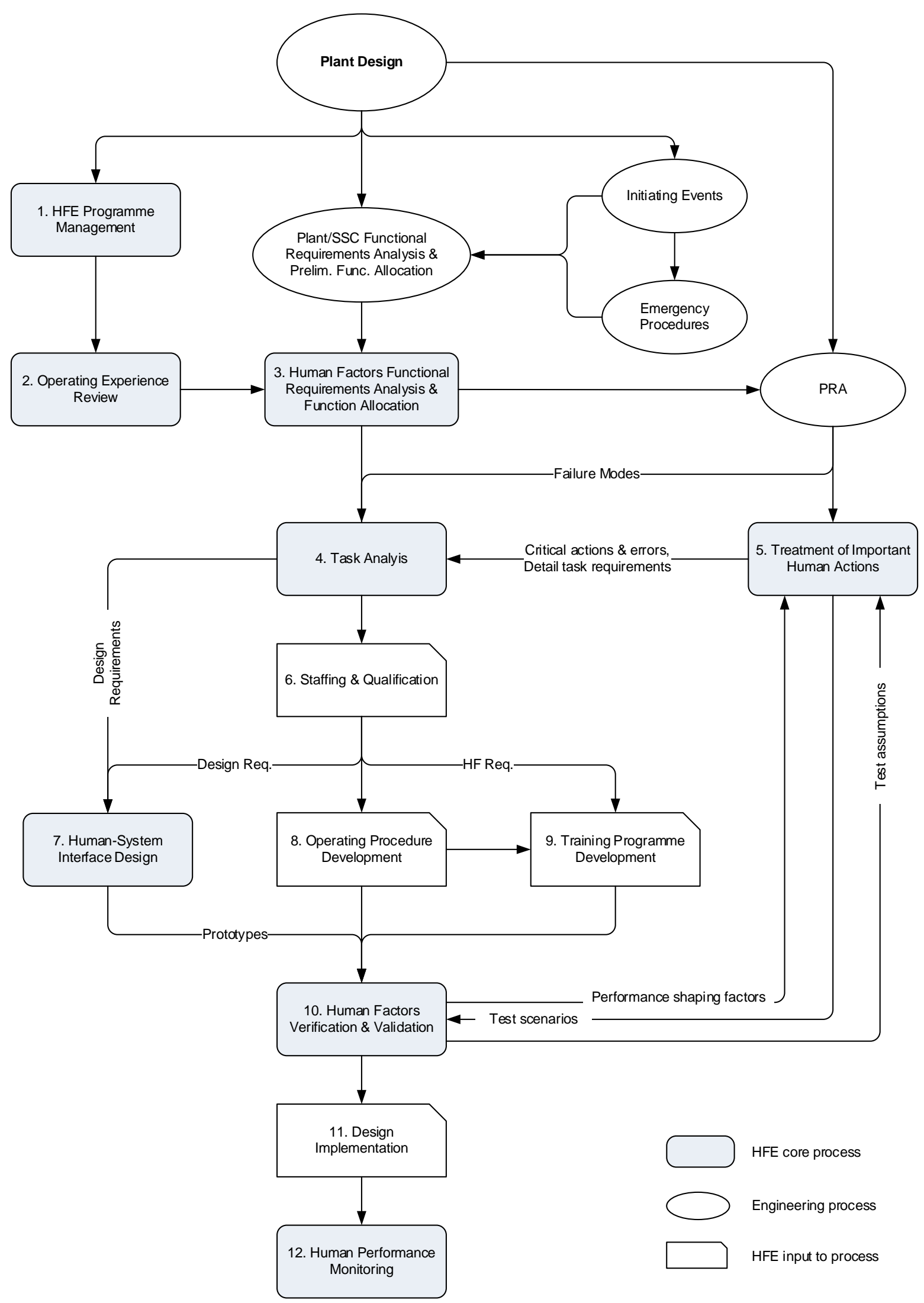

Figure 4: Human Factors Engineering Process (NUREG-0711) 


\subsubsection{Development of an HFE Graded Approach}

The plant's HFEPP will describe the HFE activities that should be performed for a modification and how the activities should be tailored according to the extent of the change and scope of the HFE impact. Because of the wide range in the scope and importance of the changes that will be made to the plant over time, it is important to apply a graded approach to HFE for modifications.

It is important for all stakeholders to understand that not all HFE work need the same amount of effort in every project. “Graded approach” simply means that not all the HFE activities outlined by NUREG-0711 are necessarily performed for every function or system that will be modified, or performed to the same level of detail. This is not only because of resource constraints, but because the emphasis in HFE clearly needs to be on those engineering activities that contribute the most to safe and efficient human tasks. Instead, only the activities indicated by the results of a screening analysis for high-risk changes must be conducted and documented to the appropriate level of detail, and yet be sufficiently flexible that it does not over-burden smaller, lower-risk changes with unnecessary HFE activities and documentation. Some of the HFE program elements may not apply at all for a given modification and thus the overall HFE program has to be tailored to the scope or extent of the change. A graded approach to HFE analyses is therefore needed whenever:

- There are clear indications that the engineering work will impact human performance to varying degrees;

- Tasks that must be analyzed are unfamiliar or no prior records exist to support the analysis;

- The modification or new design involves new technology or design concepts;

- Regulatory requirements indicate that not all aspects of the modification will affect the plant's licensing basis;

- Human-related risks resulting from the new design or modification cannot be quantified using readily available information;

The definition of the graded approach will include the level of analysis, documentation, and actions necessary to comply with stated requirements and the following considerations:

1. The purpose and mission of the plant,

2. The life cycle stage of the project and the plant,

3. The particular characteristics of the plant,

4. The scope, complexity, uncertainty, and risk level of the modification being undertaken, and

5. The risk importance of the change, as indicated by the 50.59 evaluation, including the relative importance to nuclear safety, risk to personnel safety, and risk to plant reliability and economic operation.

Implementation of this approach therefore needs the following:

- A basis for grading and bounding the scope of the work required;

- Definition of grading categories;

- Validation of grading categories against regulatory requirements, health and safety requirements, and industry best practice;

- Application of the grading categories to specific HFE program elements.

Applying these principles will determine the depth and rigor of the HFE analyses and related activities that are required and the level of documentation that should be created for all control room modifications. This will ensure that all required HFE activities are performed at an appropriate level of rigor and detail. 
This should minimize unnecessary work, minimize risk significance, and ensure that resources are focused where they are needed to meet safety, performance, and reliability goals.

\subsubsection{Identification of the Required Level of HFE Activities.}

The HFE Level is derived from an assessment of the risk of the modification to nuclear safety, power production, investment, and personnel safety.

Three levels of HFE effort are sufficient to use HFE resources effectively and to achieve maximum safety, operational, and maintenance design benefit from the HFE process. Using three different levels of effort implies that a distinction is made between the following:

1. Detail, complex work that involves the potential to affect the plant's licensing basis (due to modifications to safety-related systems),

2. Moderately complex modifications that have the potential to affect operator actions during normal operations, and

3. Low-level work that requires minimal intervention by HFE specialists.

These levels (adapted from EPRI 3002004310) are defined as follows:

\subsubsection{HFE Level 1}

When the project plan includes modification of any component or function that will either affect a fundamental safety function, modify or replace an existing safety-related system (i.e. a Class $1 \mathrm{E}$ system), or significantly affect operator performance, extensive HFE work that covers all elements described in NUREG-0711 will be required.

This level typically includes all the HFE elements defined in NUREG-0711 and to develop Results Summary Reports (RSRs) for all HFE work conducted. If a fundamental safety function is affected (as shown in Figure 2, it will also be necessary to conduct a 10 CFR 50.59 evaluation.

\subsubsection{HFE Level 2}

When the planned modification does not affect a fundamental safety function or a safety-related system, but may affect operator performance, HFE work that covers only specific elements described in NUREG0711 will be required.

The responsible engineer, working with the HFE specialists and other stakeholders, should apply criteria based on NUREG-0711, such as [13], to verify the specific HFE activities needed for the particular modification. Plans for those activities, including who will perform them and at what stage of the modification, should be included in the overall project plan for the modification.

\subsubsection{HFE Level 3}

When the planned modification does not affect a fundamental safety function, safety-related system, or operator performance in any measurable way, only low-level HFE work may be required. This involves, for example, a structured listing of the identified tasks with minimal analyses required of key systems and functions, followed by implementation of standard HSIs for those functions.

For modifications assigned to this level, the needed HFE activities would be described in a detailed project plan, which would form part of the HFEPP. 


\section{DISCUSSION}

Control room modernization poses significant engineering challenges and risks, not only to plant operations, but also to the plant's licensing basis. Early planning and familiarization with appropriate guidance and standards documents can reduce the cost of activities related to regulatory compliance and can minimize licensing risk.

As pointed out in EPRI 1010042, a disciplined process is an important success factor in the overall modernization project. This includes not only a rigorous integration of all engineering disciplines, but also adherence to regulatory guidance, acknowledged international standards, and proven industry best practice. However, a well-designed process by itself is not enough. Success in a control room modernization effort also requires a combination of management commitment to good HFE, and a willingness to commit appropriate resources and time to the total effort. This requires, in addition, people with the skills, knowledge and experience needed to carry out the HFE effort.

At the planning stage it is important for all stakeholders to review the potential licensing impacts of the changes that will be made over the course of the modernization program, and the possible interactions with NRC on human factors and human performance issues related to the modernization.

The early review process will typically provide answers to questions related to licensing and regulatory compliance. Those questions are covered in detail in reference sources like EPRI 1010042, EPRI 3002004310, and NEI 01-01 and will not be repeated in this report.

Several actions can be taken at the planning stage to help minimize the cost and risk associated with licensing and regulatory compliance. For example, as indicated in NUREG-0711, it would be beneficial to include licensing personnel in the project team. They will be able to facilitate regular communication with the NRC, assist with the interpretation of complex regulatory requirements, and especially with the 10 CFR 50.59 evaluation, if necessary. Also, the project's HFE lead will ensure that the plant's HFEPP is up to date, or updated to include modernization requirements.

The various guidance resources identified in this report all have one objective in mind: to provide a roadmap to the various regulatory requirements and guidance documents that apply to plant modifications. Following the basic steps in the licensing process described in these documents will help all stakeholders to understand how the various regulations, guides, and standards could be integrated into a plant's strategic modernization plan. It will also help to clarify the role of the utility and how they can work with regulators, inspectors, and various industry experts, including HFE specialists.

As indicated before, much of the licensing and human factors guidance available today is a result of lessons learned from the TMI accident. This includes requirements for state-of-the-art human factors principles to be employed in control room design, and that HFE be part of the plant's program to improve plant procedures.

Addressing all of the issues in current guidance and regulations require licensees to identify all previous licensing commitments that relate to safety monitoring and control, as well as control room HSIs, including commitments related to post-TMI requirements. This process is sometimes perceived by some to be so onerous that they would rather avoid any modifications that might affect the plant's licensing basis. This is unfortunate, because modernization programs offer an opportunity to improve the design of HSIs not only to improve human performance, but also to improve safety monitoring and control and to better integrate upgraded systems into the overall control room. The intent of this report is therefore to demystify and simplify the integration of regulatory requirements into the HFE process and to identify options for evaluation of the various criteria. 
THIS PAGE INTENTIONALLY BLANK 


\section{CONCLUSION}

This report aimed to describe the specific goals of control room modernization projects from a human factors engineering perspective, with specific emphasis on a few basic guidelines:

- Planning for regulatory and licensing activities, which should be done early as part of planning for the overall modernization program.

- Reviewing and understanding the applicable regulatory requirements and NRC expectations

- Performing engineering evaluations as part of the design effort and providing the information needed to support the 10 CFR 50.59 evaluation.

- $\quad$ Performing the HFE aspects of engineering evaluations for digital I\&C upgrades.

- Determining whether the modification requires any changes to the Technical Specifications, as described in NEI 01-01. Even where a modification does not require a change to the Technical Specifications, it may be desirable to update the Technical Specifications in order to take full advantage of the digital I\&C technology being installed - for example, to reduce surveillance testing burden by extending surveillance intervals.

- Screening the change using the 10 CFR 50.59 process and when it is required, performing the 10 CFR 50.59 evaluation.

- $\quad$ Preparing LAR submittals, if necessary, and other NRC communications. 
THIS PAGE INTENTIONALLY BLANK 


\section{REFERENCES}

[1] U.S. Code of Federal Regulations, Part 50.59 Changes, Tests and Experiments. Washington, DC: U.S. Government Printing Office.

[2] NRC (2014). NRC Inspection Manual - Part 9900: Operability Determinations and Functionality Assessments for Resolution of Degraded and Nonconforming Conditions Adverse to Quality or Safety. U.S. Nuclear Regulatory Commission: Washington, DC.

[3] NEI (2002). Guideline on Licensing Digital Upgrades: A Revision of EPRI TR-102348 to Reflect Changes to the 10 CFR 50.59 Rule. NEI 01-01. Nuclear Energy Institute: Washington, D.C.

[4] NEI (2000). Guidelines for 10 CFR 50.59 Evaluations. NEI 96-07 Rev 1. Nuclear Energy Institute. Washington, D.C.

[5] IAEA (2001). Modifications to Nuclear Power Plants. Safety Guide No. NS-G-23. International Atomic energy Agency, Vienna.

[6] IEEE (2004). Recommended Practice for the Application of Human Factors Engineering to Systems, Equipment, and Facilities of Nuclear Power Generating Stations and Other Nuclear Facilities. IEEE Power Engineering Society: New York, NY

[7] INL (2014). Baseline Human Factors and Ergonomics Support of Control Room Modernization at Nuclear Power Plants. (INL/EXT-14-33223). Idaho National Laboratory: Idaho Falls, ID.

[8] EPRI (2015). Human Factors Guidance for Control Room and Digital Human-System Interface Design and Modification: Guidelines for Planning, Specification, Design, Licensing, Implementation, Training, Operation, and Maintenance for Operating Plants and New Builds. (EPRI Report 3002004310). Electric Power Research Institute: Palo Alto, CA.

[9] EPRI (2005). Human Factors Guidance for Control Room and Digital Human-System Interface Design and Modification": Guidelines for Planning, Specification, Design, Licensing, Implementation, Training, Operation, and Maintenance. (EPRI report TR-1010042), Electric Power Research Institute: Palo Alto, CA.

[10] NRC (2004). Human Factors Engineering Program Review Model (NUREG-0711, Rev. 2). Washington, DC: U.S. Nuclear Regulatory Commission.

[11] NRC (2002). Human System Interface Design Review Guidelines (NUREG-0700 Rev.2). Washington, DC: U.S. Nuclear Regulatory Commission.

[12] NEI (2007). The Nuclear Regulatory Process. NEI 07-06. Nuclear Energy Institute: Washington, D.C.

[13] Boring, R.L., Ulrich, T.A., Joe, J.C., \& Lew, R.T. (2015). Guideline for Operational Nuclear Usability and Knowledge Elicitations (GONUKE). Procedia Manufacturing, 3, 1327-1334.

[14] NEI (2016). Guidance for Addressing Digital Common Cause Failure. NEI 16-16. Nuclear Energy Institute. Washington, D.C.

[15] NRC (1987/2016). Standard Review Plan (NUREG-0800). Washington, DC: U.S. Nuclear Regulatory Commission.

[16] NRC (2011). Digital Instrumentation and Controls Interim Staff Guidance, Task Working Group \#6: Licensing Process (DI\&C-ISG-06). Washington, DC: U.S. Nuclear Regulatory Commission.

[17] NRC (1980). Clarification of TMI Action Plan Requirements (NUREG-0737). Washington, DC: U.S. Nuclear Regulatory Commission. 